\title{
INTERPRETIVE SUMMARIES, JULY 2010
}

Extracellular secretion in Bacillus subtilis of a cytoplasmic thermostable $\beta$-galactosidase from Geobacillus stearothermophilus. By Xia et al., page 2838. The thermostable $\beta$-galactosidase from Geobacillus stearothermophilus has potential application in dairy industry. In this report, this cytoplasmic enzyme was secreted extracellularly in Bacillus subtilis by mediation of twin-arginine signal peptide. The extracellular enzymatic activity reached about $44 \%$ of the total enzymatic activity synthesized at $18 \mathrm{~h}$ of cultivation of the recombinant strain. Coexpression of the Bacillus subtilis twin-arginine translocase subunits was indispensable for the secretion of the target enzyme.

Ultraviolet-absorbing compounds in milk are related to forage polyphenols. By Besle et al., page 2846. Polyphenols in forages and ultraviolet-absorbing compounds (UAC) in cow milk were measured in 6 diets: a concentrate-rich diet containing cocksfoot hay, maize silage, rye grass silage, rye grass hay, mountain grassland hay, and mountain grassland pasture. The amount of UAC in the forages and milk and their composition varied widely, with grassland pasture providing by far the most UAC in diets and milks. A close relationship was found between UAC in milks and the corresponding diets. Ultraviolet-absorbing compounds are thus of potential interest for traceability of diets. They may also have a bioactive effect for milk preservation or on human health.

Composition and distribution of fatty acids in triglycerides from goat infant formulas with milk fat. By Prosser et al., page 285\%. This study examined the fatty acid profile of infant formula made from goat milk with a 55:45 mix of goat milk fat and a selection of vegetable oils. The fatty acid profile of this formula met the key fatty acid recommendations for formula for healthy infants and had $31 \%$ of palmitic acid in the $s n-2$ position of triglycerides.

Milk quality as affected by feeding regimens in a country with climatic variation. By Larsen et al., page 2863. Dairy products may be marketed as high-end products because of a specific history or a specific composition. We studied the variation in milk composition between farm types in central and southern Sweden and found a higher content of polyunsaturated fatty acids and carotenoids in milk from central Sweden compared with milk from southern Sweden, whereas differences between organic and conventional milk from central Sweden were minor. The differences were related to higher use of legumes in central Sweden and use of maize silage in southern Sweden.
Effect of exopolysaccharide-producing strains of Streptococcus thermophilus on technological attributes of fat-free lassi. By Behare et al., page 2874. A promising exopolysaccharide (EPS)-producing strain of Streptococcus thermophilus, isolated from traditionally made fermented milk (dahi) has been used to prepare a popular Indian fermented milk (lassi) that is similar to drinking yogurt. Lassi made using EPS cultures showed significantly higher viscosity, less whey separation, and better sensory scores than lassi made with non-EPS-producing control cultures. Use of EPSproducing culture reduces the amount of additives like stabilizers and produces good lassi from reduced-fat or fat-free milk, resulting in lower cost of production. The EPS-producing cultures could be exploited as starter for the manufacture of a variety of fat-free and low-fat fermented milk products.

Molecular identification of naturally occurring bacteriocinogenic and bacteriocinogenic-like lactic acid bacteria in raw milk and soft cheese. By Ortolani et al., page 2880. The present study demonstrates the presence of autochthonous lactic acid bacteria in raw milk and cheese, showing their variability in bacteriocin or bacteriocin-like substance production. These results will lead to further studies on the characterization of their bioconservation potential.

Influence of whipping temperature on the whipping properties and rheological characteristics of whipped cream. By Ihara et al., page 2887. The effects of whipping temperature on the whipping and rheological properties of whipped cream were studied. Fat globule aggregation and air bubble factors were measured to investigate the mechanism of whipping. From the results, the temperature range of 7.5 to $12.5^{\circ} \mathrm{C}$ is recommended for making whipped creams with a good texture, and a specific temperature should be decided while taking into account the preferred overrun. The results of this study also suggest that whipping temperature influences fat globule aggregation and the properties of air bubbles in whipped cream, which alters its rheological properties.

Proteolysis, lipolysis, volatile compounds, texture, and flavor of Hispánico cheese made using frozen ewe milk curds pressed for different times. By Picon et al., page 2896. Hispánico cheese is manufactured from a mixture of cow and ewe milk. To overcome ewe milk shortage in summer and autumn, curd from spring ewe milk may be frozen and used for cheese-making some months later. In the present work, ewe milk curds pressed for 15,60 , or 120 min were held 
at $-24^{\circ} \mathrm{C}$ for $4 \mathrm{mo}$, thawed, and mixed with fresh cow milk curd for the manufacture of experimental cheeses. Control cheeses were made from a mixture of pasteurized cow and ewe milk. Differences in lactic acid bacteria counts, enzymatic activity, proteolysis, lipolysis, volatile compounds, texture, and flavor characteristics between experimental and control cheeses, when recorded, were of minor practical significance.

Inhibitory effect of $\alpha_{\mathrm{S}^{-}}$and $\alpha_{\mathrm{S}^{2}}$-casein hydrolysates on angiotensin I-converting enzyme in human endothelial cells in vitro, rat aortic tissue ex vivo, and renovascular hypertensive rats in vivo. By Rousseau-Ralliard et al., page 2906. Two milk trypsin hydrolysates $\left(\mathrm{CH}_{1}\right.$ and $\left.\mathrm{CH}_{2}\right)$ were evaluated on their ability to regulate blood pressure by inhibiting angiotensin converting enzyme. Even though both peptides inhibited angiotensin converting enzyme activity in a cultured vascular cell model, they failed to modify the contracting response of aorta rings induced by angiotensin in vitro. However, systolic blood pressure of hypertensive rats fed $\mathrm{CH}_{1^{-}}$or $\mathrm{CH}_{2}$-enriched diet for $4 \mathrm{wk}$ decreased slightly. Only $\mathrm{CH}_{1}$ decreased heart rate significantly during the night.

Association between uterine disease and indicators of neutrophil and systemic energy status in lactating Holstein cows. By Galvão et al., page 2926. Neutrophil function depends on glucose for the energy required for chemotaxis, and on glycogen stores for phagocytosis and microbial killing. During transition to lactation, there is a decrease in glucose availability, which could decrease polymorphonuclear neutrophil (PMN) glycogen stores, contribute to the loss of PMN function around calving, and mediate susceptibility to uterine disease. We evaluated PMN glycogen concentration and blood glucose in cows that developed metritis or subclinical endometritis and in cows that remained healthy. We observed that cows that developed uterine disease had reduced neutrophil glycogen stores compared with healthy cows, which could be a predisposing factor for the disease.

Disruption of cell junctions induces apoptosis and reduces synthetic activity in lactating goat mammary gland. By Ben Chedly et al., page 2938. The disruption of mammary epithelium integrity is generally associated with a decrease in milk secretion. In this study, we induced mammary epithelium disruption with intramammary infusions of ethylene glycolbis(2 aminoethylether)-N,N, $\mathrm{N}^{\prime}, \mathrm{N}^{\prime}$-tetraacetic acid and lactose. We observed an increase in programmed cell death and a decrease in synthetic activity in the disrupted mammary epithelium. Both cell death and synthetic activity were regulated at the transcriptional level.
Noninvasive detection of hepatic lipidosis in dairy cows with calibrated ultrasonographic image analysis. By Starke et al., page 2952. The diagnostic accuracy of a novel method of calibrated digital analysis of transcutaneous hepatic ultrasonographic images (computer-aided ultrasound diagnosis) for diagnosis of hepatic lipidosis was studied in 151 dairy cows. Hepatic triacylglycerol content served as gold standard. High correlations were found between hepatic triacylglycerol and mean echo level $(\mathrm{r}=0.6)$ and residual attenuation $(\mathrm{r}=0.8)$. The accuracy to distinguish mild, moderate, and severe hepatic lipidosis was higher than $90 \%$. The computer-aided ultrasound diagnosis methodology and software for digital analysis of liver ultrasonographic images appears to be feasible for noninvasive screening of fatty liver in dairy herd health programs.

Diagnosing intramammary infections: Evaluating expert opinions on the definition of intramammary infection using conjoint analysis. $B y$ Andersen et al., page 2966. The criteria used to define intramammary infection in an udder quarter vary greatly in scientific studies. The primary purpose of this study was to develop a pseudo-gold standard by evaluating expert opinions on the topic. Conjoint analysis, a survey tool commonly used in marketing analysis, was used to extract a set of criteria to classify quarters as infected or not using data from 3 consecutive quarter milk samples taken 1 wk apart. These criteria will serve as a consensus standard when evaluating single sample definitions in the pursuit of a common, defensible definition of an intramammary infection.

Effect of reducing the period of follicle dominance in a timed artificial insemination protocol on reproduction of dairy cows. By Santos et al., page 2976. Hormonal programs are used for systematic management of reproduction in dairy herds to optimize insemination rates. Such programs must not compromise pregnancy per artificial insemination $(\mathrm{P} /$ AI); otherwise, reproductive performance would suffer. Improvements in P/AI of cows subjected to these programs require that they follow physiological principles. When the period of follicle dominance in timed AI programs is reduced to 5 or $6 \mathrm{~d}$, embryo quality improves. Reducing the interval between follicle recruitment and insemination from 10 to $8 \mathrm{~d}$ improved P/AI. Because the protocol required regression of a younger corpus luteum, an additional treatment with prostaglandin was needed to optimize synchronization.

Effect of nonclinical Staphylococcus aureus or coagulase-negative staphylococci intramammary infection during the first month of lactation on somatic cell count and milk yield in heifers. By Paradis et al., page 2989. A study was conducted 
to determine the effect of an intramammary infection caused by Staphylococcus aureus or coagulase-negative staphylococci during the first month of lactation on somatic cell count and milk production in heifers during the first lactation. These infections had no effect on milk production. Both Staphylococcus aureus and coagulase-negative staphylococci infections had a significant sustained effect on milk quality because infected heifers had a higher somatic cell count than uninfected heifers for the entire first lactation.

Dairy farmer attitudes and empathy toward animals are associated with animal welfare indicators. By Kielland et al., page 2998. Attitudes and empathy of farmers are likely to influence human-animal interaction and thereby affect the behavior of farmers toward animals and, consequently, animal welfare. Attitudes and empathy of farmers toward animals were assessed using a photo-based pain assessment instrument. A total of 221 farmers were sampled via e-mail and 154 responses were obtained (70\% response rate). Associations were found between empathy and attitudes and between empathy, milk production, and the prevalence of skin lesions. Farmers who want to improve animal welfare could benefit from changing and improving the manner in which animals are handled.

Differences in milk production, glucose metabolism, and carcass composition of 2 CharolaisHolstein $F_{2}$ families derived from reciprocal paternal and maternal grandsire crosses. By Hammon et al., page 300\%. Lactation performance, glucose metabolism, and carcass composition were investigated in 2 Charolais $\times$ German Holstein families comprising full and half sibs that shared identical but reciprocal paternal and maternal Charolais grandfathers. The 2 families markedly differ in milk production, glucose metabolism, and carcass composition, indicating differences in nutrition partitioning between the 2 families. Therefore, sex chromosomal effects maybe an important regulatory mechanism of milk performance and nutrient partitioning in cattle.

Assessing ovulation detection performance in commercial dairy herds using progesterone concentrations from limited numbers of strategically collected milk samples. By Morton and Wynn, page 3019. In dairy herds in which artificial insemination is used, management strategies are necessary to identify cows in which ovulation is imminent and it is important to measure herd ovulation detection performance. A method was developed to assess ovulation detection performance in commercial dairy herds; the method was successfully implemented in the majority of 167 herds. This approach will help managers of commercial dairy herds and their consultants more accurately assess ovulation detection performance. Performance var- ied among herds, indicating the potential for increased reproductive efficiency through better ovulation detection performance.

Colostrogenesis: Mass transfer of immunoglobulin $\mathbf{G}_{1}$ into colostrum. By Baumrucker et al., page 3031. The formation of colostrum in dairy cows is extremely important to the dairy industry. Colostrum concentration of antibodies is extremely variable, with many cows providing enough antibodies to the calf to adequately reduce disease risk. We show that the range in the mass of immunoglobulin $\mathrm{G}_{1}$ in colostrum of individual cows is large and indicates large differences in immunoglobulin $\mathrm{G}_{1}$ transfer capacity. Approximately $10 \%$ of tested animals show very high capacity to transfer antibodies into the first colostrum. High transfer capacity is found in all parities and is not related to mammary secretory tissue mass.

Effects of intravenous glucose infusion and nutritional balance on serum concentrations of nonesterified fatty acids, glucose, insulin, and progesterone in nonlactating dairy cows. $B y$ Vieira et al., page 304\%. Insulin and progesterone are important hormones for reproduction in dairy cows. They affect length of anestrous period, cow fertility, and embryo development. However, their circulating concentrations and metabolic effects vary according to cow nutritional status. In this study, intravenous glucose infusion increased blood concentrations of insulin and progesterone in cows with adequate nutrient intake, whereas cohorts in negative nutritional balance experienced only increased insulin concentrations. In the dairy industry, cows experience negative nutritional status at the beginning of the lactation; therefore, further research is required to better understand the relationship between nutritional status, insulin, progesterone, and reproduction in dairy cattle.

Short communication: Ketone body concentration in milk determined by Fourier transform infrared spectroscopy: Value for the detection of hyperketonemia in dairy cows. By van Knegsel et al., page 3065. The objective of this study was to evaluate the use of Fourier transform infrared spectroscopy predictions of $\beta$-hydroxybutyrate (BHBA) and acetone in test-day milk to detect cows with hyperketonemia (based on BHBA in plasma). This study showed that Fourier transform infrared spectroscopy predictions of BHBA or acetone in milk can detect cows with hyperketonemia with a higher accuracy than milk fat:protein ratio, but the high proportion of false positives limits practical applicability.

Short communication: Risk of severe heel erosion increased with parity and stage of lactation in freestall-housed dairy cows. By Chapinal et al., 
page 30\% . Heel erosion is the most prevalent hoof lesion in housed dairy herds, particularly in freestall facilities. Fifty-seven animals were used to assess changes in the risk of heel erosion from the dry period to mid lactation in primiparous and multiparous dairy cows housed in freestalls. Multiparous cows had a higher relative risk of developing heel erosion than primiparous cows, and the risk increased more rapidly as lactation progressed. In conclusion, stage of lactation and parity were major risk factors for severe heel erosion in dairy cattle housed in freestalls.

Technical note: A simple model to estimate changes in dietary composition of strip-grazed cattle during progressive pasture defoliations. By Romera et al., page 3074. Severe methodological problems occur in measuring dietary quality during short-term progressive pasture defoliations during grazing $(4$ to $24 \mathrm{~h})$. A mechanistic, simple, and practical model of changes in dietary quality of pasture grazed by dairy cows is presented. It uses green proportion of the herbage mass and proportion of herbage mass eaten, optionally complemented with inputs of herbage chemical composition, and outputs changes in diet composition. The model could be useful for those interested in interfacing animal and pasture models of grazing cattle.

Effects of pair versus single housing on performance and behavior of dairy calves before and after weaning from milk. By De Paula Vieira et al., page 3079. Dairy calves are typically separated from the cow soon after birth and housed in single pens for the milk-feeding period. Little research to date has examined the effect of social housing on the early development of dairy calves. This study demonstrates that pair housing results in increased intakes of starter during the milk feeding period, decreased number of distress calls at weaning from milk, and improved performance of dairy calves after weaning.

Prepartum dietary management of energy intake affects postpartum intake and lactation performance by primiparous and multiparous Holstein cows. By Janovick and Drackley, page 3086. The effect of prepartum energy intake on dry matter intake, body condition, milk yield, milk composition, and energy balance was studied in primiparous and multiparous Holstein cows. Prepartum energy intake did not affect milk yield or composition; however, regardless of parity group, cows that overconsumed energy prepartum with respect to their requirements experienced large decreases in dry matter intake prepartum, had greater loss of body condition postpartum, and had larger changes in energy balance compared with cows that had their energy intake controlled or restricted prepartum.
Regulation of protein synthesis in mammary glands of lactating dairy cows by starch and amino acids. By Rius et al., page 3114. Mid-lactation dairy cows were fed restricted diets and infused abomasally with starch, or casein, or both. Treatment effects on milk yield, the kinetics of mammary nutrient uptake, and mammary cell signaling were determined. Cows infused with starch had an increased affinity for amino acids and increased net uptake of amino acids. Infusions of starch activated the signaling molecules ribosomal protein $\mathrm{S} 6$ and endothelial nitric oxide synthase. However, mammalian target of rapamycin activity increased in response to infusions of casein only when starch was present. Milk and protein yield increased in animals infused with starch. Therefore, the mammary glands positively responded to the supply of starch, and activation of local and intracellular mechanisms appeared to at least partially explain the greater milk and protein synthesis.

Effects of a molasses-coated cottonseed product on diet digestibility, performance, and milk fatty acid profile of lactating dairy cattle. By Mullins and Bradford, page 3128. Twelve Holstein cows were used to examine the effects of feeding a molasses-coated cottonseed product. Dietary molasses tended to alter milk fatty acid profiles in a manner suggesting that molasses was favorable to fiber-digesting bacteria. The effects of a direct-fed microbial were also examined, and milk fatty acid profiles suggested that it had an inhibitory effect on ruminal biohydrogenation. Results suggest that coating cottonseed with a hardened molasses product does not significantly depress nutrient digestibility and may provide a convenient method of incorporating these ingredients into dairy rations.

Milk composition, milk fatty acid profile, digestion, and ruminal fermentation in dairy cows fed whole flaxseed and calcium salts of flaxseed oil. By Côrtes et al., page 3146. Diets containing 4.2\% whole flaxseed, $1.9 \%$ calcium salts of flaxseed oil, or a mixture of $2.3 \%$ whole flaxseed and $0.8 \%$ calcium salts of flaxseed oil had no effect on milk production. Calcium salts of flaxseed oil increased concentrations of rumenic acid and intermediates of biohydrogenation in milk fat compared with whole flaxseed. Diets supplemented with flaxseed products had similar concentrations of $\alpha$-linolenic acid in milk fat. Results confirm that flax products supplemented at 0.7 to $1.4 \%$ of fat in the diet slightly improve the nutritive value of milk fat.

Utilization of nitrogen in cows consuming wet distillers grains with solubles in alfalfa and corn silage-based dairy rations. By Gehman and Kononoff, page 3166. Feeding high levels of wet distillers grains with solubles (WDGS) often means feeding 
rations high in $\mathrm{CP}$, potentially increasing nitrogen excretion. We hypothesized that forage type may affect nitrogen utilization in rations with WDGS. However, in this experiment, forage did not affect nitrogen utilization in rations containing 25\% WDGS. Primarily, rations containing 25\% WDGS resulted in reduced urinary and manure nitrogen excretion and increased retained nitrogen and milk and protein yield compared with rations without WDGS.

Performance and amino acid utilization of early lactation dairy cows fed regular or reduced-fat dried distillers grains with solubles. By Mjoun et al., page 3176. Two types of dried distillers grains with solubles (DG), regular and reduced-fat, were evaluated as a source of protein in early-lactation cows. Feed intake, milk yield, and fat-corrected milk were similar when either type of DG replaced soybean feedstuffs in the diet. Milk composition was similar except that milk protein percentage and yield were greater in DG diets compared with control diet. Similarly, feed and nitrogen efficiencies were improved for DG diets. Results indicate that lower dietary lysine was not a limitation when early-lactation cows were fed up to $22 \%$ of different types of DG.

Performance of high-yielding dairy cows supplemented with fat or concentrate under hot and humid climates. By Moallem et al., page 3192. Increasing milk production during the summer is of a special interest; therefore, high-yielding dairy cows were supplemented with either fat or concentrate during the hot season to enhance yields. Fat supplementation led to greater yields of milk fat and fat-corrected milk than concentrate supplementation, but not than controls. Feed utilization for milk production was higher in fatsupplemented cows than in other groups. Energy partitioning differed between groups: cows supplemented with concentrate channeled energy toward body mass deposition.

Quantifying ruminal digestion of organic matter and neutral detergent fiber using the omasal sampling technique in cattle - A meta-analysis. By Huhtanen et al., page 3203. Measurements of neutral detergent fiber and organic matter digestibility in the rumen are typically based on duodenal sampling in combination with one or more indigestible markers. Sampling at the omasum using a triple-marker system offers the advantage of minimizing endogenous secretions and reducing surgical intervention. Data from 32 studies were used to assess the reliability of this technique for determining ruminal neutral detergent fiber and organic matter digestion. Indirect comparisons revealed that omasal sampling resulted in more precise estimates of digestibility coefficients than sampling at the duodenum; this can be attributed to the use of multiple markers rather than sampling site per se.

Quantifying ruminal nitrogen metabolism using the omasal sampling technique in cattle-A meta-analysis. By Broderick et al., page 3216. Omasal sampling for quantifying ruminal nitrogen metabolism is less invasive than sampling at the abomasum or duodenum because only ruminal cannulae are required. Mixed model analysis of a large dataset indicated that the omasal sampling technique yielded useful measurements of ruminal microbial protein, rumen-degradable protein, and rumen-undegradable protein supply. Regressions of observed omasal flows on flows predicted by the National Research Council (NRC) model indicated that the NRC predicted similar total protein but greater RUP and lower microbial protein than was measured by the omasal method. These differences may have resulted because the NRC model was constructed largely using data from in situ analyses and duodenal sampling. The omasal sampling method yields valuable measurements of rumen-degradable protein, rumenundegradable, and ruminal microbial protein synthesis in dairy cattle.

Effects of partially replacing barley silage or barley grain with dried distillers grains with solubles on rumen fermentation and milk production of lactating dairy cows. By Zhang et al., page 3231. Dried distillers grains with solubles (DDGS) is a byproduct of ethanol production. The partial replacement of barley silage with DDGS improved the productivity of lactating dairy cows without causing rumen acidosis. In addition, DDGS can partially replace barley grain in diets for lactating dairy cows without negative effects on productivity.

Effects of feeding alfalfa hay on chewing, rumen $\mathrm{pH}$, and milk fat concentration of dairy cows fed wheat dried distillers grains with solubles as a partial substitute for barley silage. By Zhang et al., page 3243. Wheat-based dried distillers grains with solubles is available in western Canada as a byproduct of ethanol production. Feeding wheat-based dried distillers grains with solubles in place of barley silage increased milk production of lactating dairy cows, but chewing time, rumen $\mathrm{pH}$, and milk fat concentration were decreased and dietary inclusion of alfalfa hay did not alleviate such responses.

The effect of harvesting strategy of grass silage on digestion and nutrient supply in dairy cows. By Kuoppala et al., page 3253. Dairy cows were fed 4 different diets based on grass silages harvested at 2 stages of growth in primary growth and regrowth. The lower milk production in cows fed regrowth grass 
silages compared with primary growth silages could be attributed to the lower silage intake. Lower intake of regrowth silages could not be attributed to chemical composition of the silages, rumen fill, digestion and passage kinetics of neutral detergent fiber, or the ratio of protein to energy in absorbed nutrients.

Changes in production and mammary metabolism of dairy cows in response to essential and nonessential amino acid infusions. By Doepel and Lapierre, page 3264. Eight Holstein cows were used to determine alterations in mammary gland metabolism in response to a variable amino acid (AA) supply. Milk and milk protein yield increased in response to the supplementation of essential AA without a concurrent increase in mammary glucose uptake but with an increase in uptake of essential AA and other energetic substrates. This response to essential AA supplementation demonstrates the metabolic priority of milk production and the flexibility of the mammary gland to use various substrates at its disposal.

Technical note: Use of accelerometers to describe gait patterns in dairy calves. By de Passillé et al., page 328\%. In this study, we attached a triaxial accelerometer in the hind legs of calves and described the pattern of acceleration associated with various gaits in calves. We were able to accurately estimate the number of steps taken by the calves by counting the number of peaks in the forward axis and to classify the gait as walking, trotting, or running by using the median interpeak interval.

Monitoring inbreeding trend and inbreeding depression for economically important traits of Holstein cattle in Iran. By Rokouei et al., page 3294. Inbreeding is the mating of animals that are related to each other. It may increase a higher expression of deleterious recessive alleles, resulting in adverse effects on the most economically important traits. In the present study, inbreeding level and its effect on production, reproduction, somatic cell score, calving ease, and longevity traits in Iranian Holsteins were investigated. Whereas the average inbreeding coefficient was lower than the corresponding estimates reported for the Holstein breed in the most developed country, the rate of inbreeding in the current study was considerably higher, indicating that imported semen from elite bulls has been used. Furthermore, the significant reduction in almost all performances because of a $1 \%$ increase in inbreeding suggests that avoidance of mating between close relatives is crucial in breeding programs.

Genome-wide scan to detect quantitative trait loci for milk urea nitrogen in Dutch HolsteinFriesian cows. By Bouwman et al., page 3310. Many Dutch dairy farms produce more nitrogen in manure than they are allowed to use on their land, according to the Dutch manure policy. This leads to disposal costs of manure surplus. In the Dutch manure policy, milk urea nitrogen (MUN) is used to estimate nitrogen excretion of dairy cows. Reducing MUN is economically favorable for dairy farmers and leads to a reduction of environmental pollution. Variation in MUN is partly attributed to genetics. In this study, suggestive chromosomal regions have been detected affecting MUN. This is a first step towards unraveling the genetic basis of differences in nitrogen efficiency between cows.

A validated genome-wide association study in 2 dairy cattle breeds for milk production and fertility traits using variable length haplotypes. By Pryce et al., page 3331. A genome-wide association study in 2 dairy cattle breeds confirmed several previously reported mutations affecting milk production traits and discovered several novel mutations, including a genomic region that had an effect on fertility in both Holsteins and Jerseys. Associations were detected with either single nucleotide polymorphism markers or haplotypes of single nucleotide polymorphism alleles. The precision of quantitative trait loci mapping increased with haplotype length, as did the number of validated haplotypes discovered, especially across breed.

Short communication: Influence of composite casein genotypes on additive genetic variation of milk production traits and coagulation properties in Holstein-Friesian cows. By Penasa et al., page 3346. The effect of composite $\beta$ - and $\kappa$-casein genotypes on genetic parameter estimation of milk coagulation ability, milk yield, and quality aspects was investigated in Italian Holstein-Friesian cows. Inclusion of composite genotypes led to a decrease of 47 and $68 \%$ in the additive genetic variance for rennet coagulation time and curd firmness, respectively, 18 and $23 \%$ for $\mathrm{pH}$ and titratable acidity, respectively, and less than $6 \%$ for other milk quality traits. Heritability decreased from 0.25 to 0.14 for rennet coagulation time and from 0.12 to 0.04 for curd firmness, and estimates of genetic correlations between traits slightly differed when composite genotypes were included in the analysis.

Identifying cost-minimizing strategies for guaranteeing target dairy income over feed cost via use of the Livestock Gross Margin dairy insurance program. By Valvekar et al., page 3350. A new price risk management tool is available for many US dairy farmers. The Livestock Gross Margin Insurance for Dairy Cattle protects a farmer's defined income over feed cost. This insurance program may become an important tool to control increased volatility of milk and feed prices. We have created an optimization model to help dairy farmers identify the least cost contract design to achieve desired income over feed cost targets. 
Our results indicate that optimal contract designs vary with changes in these income targets.

Somatic cell count assessment at the quarter or cow milking level. By Mollenhorst et al., page 3358. The aim was to investigate whether on-line somatic cell count assessment should be implemented by the udder quarter or at the cow level when both are combined with electrical conductivity at the quarter level. Quarter-level somatic cell count assessment was superior to cow-level assessment; however, economic considerations and farmer preferences must be considered because differences in detection performance are probably too small to decide on that basis alone.

Excellence in teaching for promotion and tenure in animal and dairy sciences at doctoral/ research universities: A faculty perspective. By Wattiaux et al., page 3365. Animal and dairy science faculty at 27 research universities in the United States responded to a survey about evaluation of teaching as part of the promotion and tenure process of assistant professors. Faculty reported that use of a teaching portfolio would be desirable, but is currently underemphasized. In contrast, student evaluations, publishing peer-reviewed manuscripts, and authoring a textbook or book chapter are considered important but currently overemphasized. Most faculty were either not informed at the time of hiring or were informed only verbally of how teaching would be evaluated for promotion and tenure. Recommendations are made for improvements in the process.

Effects of spontaneous heating on estimates of total digestible nutrients for alfalfa-orchardgrass hays packaged in large round bales. By Coblentz and Hoffman, page 3377. In a series of 3 harvests from the same research site, large round bales of alfalfaorchardgrass hay were made at preset bale diameters of $0.9,1.2$, or $1.5 \mathrm{~m}$ and at moisture concentrations ranging from 9.3 to $46.6 \%$. Internal bale temperatures were monitored for these hays during an outdoor storage period. Concentrations of total digestible nutrient (TDN) in hays were calculated by summative equations. Different (greater) estimates of TDN were obtained when protein-corrected neutral detergent fiber and 48-h neutral detergent fiber digestibility were used to estimate truly digestible fiber compared with estimates obtained from the acid-detergent lignin option. Regardless of which option was used to calculate truly digestible fiber, TDN was depressed as a result of spontaneous heating, primarily as a function of reduced concentrations of nonfiber carbohydrates in the hays.

The influence of strain of Holstein-Friesian cow and feeding system on greenhouse gas emissions from pastoral dairy farms. By Shalloo et al., page 3390. A newly developed submodel to quantify greenhouse gas (GHG) emissions was developed and linked to a whole farm systems model, the Moorepark Dairy System Model. The model was used to quantify the GHG emissions of 3 differing strains of HolsteinFriesian cows across 3 grass-based feeding systems. The results showed that the lowest GHG emission per unit of product and maximum profitability were achieved with cows selected for production and reproductive traits and that GHG emission per hectare decreased as herd dry matter intake decreased. 